\title{
Factors influencing drug deposition in the nasal cavity upon delivery via nasal sprays
}

\author{
Mingyue Gao ${ }^{1} \cdot$ Xin Shen $^{1} \cdot$ Shirui Mao ${ }^{1}$
}

Received: 29 February 2020 / Accepted: 5 April 2020 / Published online: 12 April 2020

(c) The Author(s) 2020, corrected publication 2020

\begin{abstract}
Background In nasal drug delivery system, nasal spray seems to be the most promising delivery method for both local and systemic diseases therapy. Nasal deposition behavior is the most basic and important process for nasal sprays, which is related to nasal mucociliary clearance, retention of a formulation in the nose therefore the therapeutic effect.

Area covered The present paper systemically summarized and discussed the factors influencing drug deposition in the nasal cavity upon delivery via nasal sprays, including device, formulation and administration techniques. Emitted dose volume of the device, spray pattern and plume geometry, droplet size distribution and velocity of emitted droplets were important device factors influencing nasal deposition. Besides, viscosity, thixotropic property and surface tension were considered to be the formulation factors influencing nasal deposition of spray. In addition, administration technique influencing nasal deposition included head orientation, administration angle, insertion depth of spray nozzle and breathing profile. Meanwhile, the imaging methods used to predict and visualize the deposition of nasal formulation was illustrated.

Expert opinion The review provided important theoretical and experimental knowledge to control the deposition pattern of nasal sprays in order to achieve better therapeutic effect in the clinic.
\end{abstract}

Keywords Nasal sprays $\cdot$ Deposition $\cdot$ Device $\cdot$ Formulation $\cdot$ Characterization

\section{Introduction}

Nasal cavity is characterized by porous epitheliums, large absorption area, rich subcutaneous blood vessels and low enzyme activity, which made it an advantageous administration route for rapid drug absorption and fast onset of action, with high drug permeability and avoidance of hepatic first-pass effect. It is not only suitable for local therapy of nasal diseases but also a novel delivery route for systemic drug delivery. Especially, some studies indicated that nasal drug delivery enhanced the bioavailability of many macromolecular drugs via different formulation strategies (Gao et al. 2019; Khafagy et al. 2010). Moreover, nasal drug delivery is regarded as a beneficial drug delivery route for the therapy of central nervous diseases due to the transport of drugs into the brain through the olfactory, trigeminal and

Shirui Mao

maoshirui@syphu.edu.cn

1 Department of Pharmaceutics, School of Pharmacy, Shenyang Pharmaceutical University, 103 Wenhua Road, Shenyang 110016, China vascular pathway. Additionally, it is also applied for vaccination, which induces both humoral and cell mediated immune responses with low doses (Tlaxca et al. 2015). Therefore, as a noninvasive drug delivery method, nasal drug delivery is an attractive administration route of small molecular or macromolecular drugs for local or systemic therapy, nose to brain drug delivery and vaccination.

According to the marketed nasal products, nasal drug preparations include nasal drops, nasal sprays, nasal aerosols and nasal ointments/creams. Marketed nasal ointments and creams are limited and employed mainly for the therapy of nasal bacterial infection and relief of nasal congestion due to their longer retention time. Nasal aerosols are mainly applied to the drug delivery of solid particles. Both nasal drops and sprays are widely used in the drug delivery of marketed liquid nasal formulations. Compared with nasal drops, nasal sprays show more advantages. For example, constant doses can be supplied by metering dose valves, ensuring the accurate therapeutic dose and preventing potential adverse effect of overdose. By using nasal sprays, the liquid formulations can be dispersed fully and evenly at the orifice of the device, enlarging the dispersed area in the nasal cavity and therefore 
avoiding the postnasal dripping and anterior leakage of the nasal droplets. Moreover, not only was marketed nasal sprays applied to deliver small molecular drugs for local and systemic therapy, but it was also used for the delivery of macromolecular drugs such as nafarelin, buserelin, desmopressin, oxytocin, salmon calcitonin and influenza vaccine for systemic therapy. Therefore, in the nasal drug delivery system, nasal sprays seem to be the most promising drug delivery method for local and systemic therapy.

Drug deposition in the nasal cavity, mucociliary clearance and mucosal absorption are the three important processes of nasal drug delivery. Deposition pattern of nasal sprays includes the deposition position and area of the formulation in the nasal cavity. Due to nasal anatomy and physiology structure, with a non-ciliated area in the anterior part of the nasal cavity and a ciliated region in the posterior part of the nose, the deposition position is of special importance for the nasal mucociliary clearance and retention of a formulation in the nose. In addition, deposition area refers to the total surface of deposition, which is related to the absorption of nasal sprays (Kublik and Vidgren 1998). Furthermore, nasal deposition pattern alone has been thought to be correlated with biological effect of nasal spray when pharmacokinetic, pharmacodynamic and clinical studies are too unreliable or impractical (Suman et al. 2002). Therefore, nasal deposition pattern is the most basic and important process for nasal formulations, especially for nasal sprays, and factors influencing nasal drug deposition should be well documented for better formulation design and decreased therapeutic variation. However, limited information is available in this area.

It was known that the deposition of a nasal spray is dependent on multiple factors including device, formulation, patient administration technique and physiological structure of the nasal cavity (Kundoor and Dalby 2010). As to the effect of physiological structure on the nasal deposition, it was indicated that higher nasal deposition efficiency could be achieved for a person with a smaller cross-sectional area, larger surface area, and longer perimeter of nasal cavity (Cheng et al. 1996). Nevertheless, for pharmaceutical researchers, the other three factors including device, formulation and patient administration technique are the major concerns while developing a nasal spray product. For example, it was reported that the formulation viscosity, administration-related variables such as spray angle and nasal spray pump design of a device had significant effect on the deposition pattern of nasal spray (Kundoor and Dalby 2011). The objective of the present paper is to systemically summarize and discuss the three factors influencing drug deposition in the nasal cavity upon delivery via nasal sprays. First of all, physiological structure and properties of nasal cavity were introduced. Thereafter, the effect of device, formulation and administration techniques on nasal deposition was summarized. Device factors included emitted dose volume of the device, spray pattern and plume geometry, droplet size distribution and velocity of emitted droplets. Viscosity, thixotropic property and surface tension were considered to be the important formulation factors influencing nasal deposition of spray. In addition, administration techniques included head orientation, administration angle, spray nozzle insertion depth and breathing profile. Meanwhile, characterization methods for nasal deposition pattern were elucidated.

\section{Physiological structure and properties of nasal cavity}

As shown in Fig. 1, the nasal cavity can be divided into several regions, including vestibule, atrium, respiratory region, olfactory region and nasopharynx. The epithelial cells in the nasal vestibule are stratified, squamous and keratinized with sebaceous glands. The atrium is a transitional epithelial region between the vestibule and the respiratory region with stratified, squamous cells anteriorly and pseudostratified columnar cells with microvilli posteriorly. The respiratory region is lined by pseudostratified columnar epithelial cells interspersed with goblet cells, seromucus ducts and the openings of subepithelial seromucus glands. Many of these cells possess actively beating cilia with microvilli. This region is supplied with the richest blood and covered the largest surface area including superior, middle and inferior nasal turbinates. Olfactory region possesses specialized

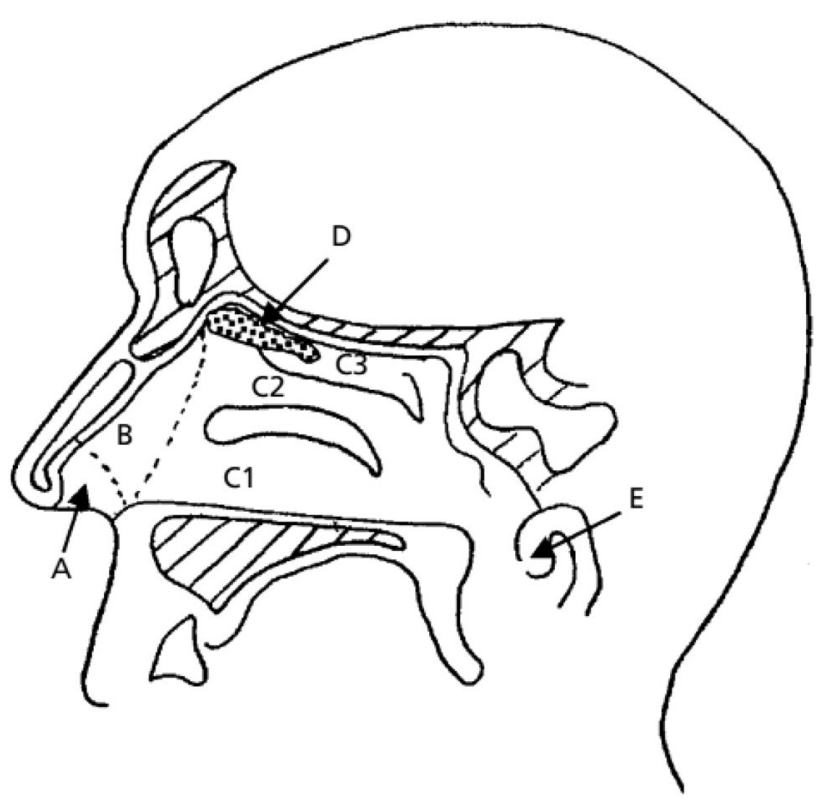

Fig. 1 Sagittal section of the nasal cavity showing the nasal vestibule $(\mathrm{A})$, atrium (B), respiratory area: inferior turbinate $(\mathrm{C} 1)$, middle turbinate $(\mathrm{C} 2)$ and superior turbinate (C3), the olfactory region (D), and nasopharynx (E). Adapted from (Ugwoke et al. 2001 with permission from John Wiley and Sons) 
ciliated olfactory nerve cells for smell perception and ophthalmic, maxillary divisions of trigeminal nerve cells, both of which have direct access to cerebrospinal fluid. Upper part of nasopharynx is ciliated cells and lower part contains squamous epithelium cells (Ugwoke et al. 2001).

Although respiratory region is the major absorption area of nasal spray, drug retention time is short under the effect of mucocilary clearance. It was found that most of the drugs in the posterior respiratory region dripped into the nasopharynx after about $30 \mathrm{~min}$ (Newman et al. 2004). However, the drug in the anterior area of this region has longer retention time, which is beneficial for the absorption of drugs for systemic effect. Olfactory region showed the potential to transport the drug to the brain and is the targeted absorption area of drugs for the therapy of central nervous diseases. Middle meatus is the best targeted position for the therapy of sinusitis disorders (Durand et al. 2001). For nasal vaccination, nasal-associated lymphoid tissue (NALT) region is the target deposition area for the higher immunogenic responses. The NALT region includes inferior, middle, superior turbinate and nasopharynx region.

\section{Device factors influencing nasal deposition}

\section{Emitted dose volume of the device}

Nasal volume ranges from 25 to $200 \mu \mathrm{L}$. Dose volume of the sprays on the market is normally $50 \mu \mathrm{L}$ and $100 \mu \mathrm{L}$. The emitted dose volume was related to the nasal deposition of the formulation. Some studies found that the formulation administered to one nostril will contribute to larger deposition area in the nasal cavity compared with the same dose administered to two nostrils. For example, application of $80 \mu \mathrm{L}$ in two nostrils covered a similar area to $140 \mu \mathrm{L}$ in a single dose (Newman et al. 1994). Harris et al. (1988a) also found that compared with $50 \mu \mathrm{L}$ two nostrils, $100 \mu \mathrm{L}$ one nostril resulted in a larger deposition area. However, although large volume one nostril contributed to larger deposition area of nasal sprays, it is not beneficial to the absorption of drugs. Newman et al. (1994) found that the initial deposition area of $80 \mu \mathrm{L}$ volume each nostril by spray pump with a lower dose of insulin was significantly smaller, it did not result in significantly higher blood glucose level. Harris et al. (1988a) showed that twofold higher bioavailability of desmopressin was generated by $50 \mu \mathrm{L}$ in each nostril compared with $100 \mu \mathrm{L}$ one nostril. It is attributed to longer retention time in human nasal cavity due to lower deposition rate in the posterior ciliated zone (Kublik and Vidgren 1998). Besides, the nasal cavity has a limited capability for drug liquid. Harris et al. (1988a) suggested that volumes larger than $100 \mu \mathrm{L}$ inevitably run drown to the posterior pharynx. Therefore, it seemed that low administration volume in each nostril leads to the preferred nasal deposition of the formulation to fulfill better absorption and therapeutic effect of the formulation, compared with the higher administration volume in one nostril. Meanwhile, low administration volume may decrease the discomfort and improve the compliance of patients (Slater et al. 2007).

\section{Spray pattern and plume geometry}

Spray plume is the term to describe the spray emitted from the device. Spray pattern and plume geometry are used to describe the spray shape which can be imaged by a horizontal and vertical laser sheet, respectively. Spray patterns are characterized by the minimum $\left(\mathrm{D}_{\min }\right)$ and maximum $\left(\mathrm{D}_{\max }\right)$ spray diameters, ovality $\left(\mathrm{D}_{\max } / \mathrm{D}_{\text {min }}\right)$ and the spray area. It was observed that there was an inverse relationship between the viscosity and ovality ratio of the nasal sprays (Kundoor and Dalby 2011). Plume angle, plume width and breakup length $\left(\mathrm{L}_{\mathrm{bu}}\right)$ are the parameters to characterize the plume geometry of nasal sprays. The breakup length $\left(\mathrm{L}_{\mathrm{bu}}\right)$ is the distance at which clearly formed particles are just observed. (Fung et al. 2013; Inthavong et al. 2012). The spray pattern and plume geometry are influenced by various factors derived from the devices and formulations, including the size and shape of the nozzle, the design of the pump, the size of the metering chamber, and characteristics of the formulation. At the same time, the parameter might also reflect the performance of the device or formulation of the nasal spray. The Food and Drug Administration (FDA) recommend that characterization of spray pattern and plume geometry is important for evaluating the performance of a pump (FDA 2002).

Among the parameters influencing the spray pattern and plume geometry, the plume angle of spray correlates closely with deposition of the formulation in the nasal cavity. It was found that the nasal spray with a wider plume angle deposited mainly in the anterior region (Cheng et al. 2001). According to the report, as the spray cone increased from 35 to 60 degree, it was difficult for the spray to penetrate through the nasal valve into the main nasal passage, leading to smaller deposition area (Newman et al. 1988). Meanwhile, the percentage of anterior deposition was reported to be linearly increased with the increment of the plume angle $(\mathrm{Pu}$ et al. 2014). However, not all the literature reported the same experimental phenomenon. It was observed that wider plume angles lead to increased posterior deposition of nasal spray (Guo et al. 2005). It might be because other characteristics of the formulation such as droplet size had a more significant influence on deposition, in which significant larger droplet size made the droplets deposited at the anterior area of the nasal cavity, weakening the effect of plume angle on the nasal deposition. In any case, it can be speculated that except for extreme conditions, narrow plume angle might be more 
suitable for narrow passageway of the nasal cavity, which made the spray penetrate the nasal valve more easily and resulted in larger deposition area in the main nasal passage.

It should be mentioned that the plume angle is the most obvious value to change within the different spray phase. It was found that the spray half cone angle was $6.54^{\circ}, 21.1^{\circ}$ and $8.0^{\circ}$ during the pre-stable, stable and post-stable stages, respectively, under the injection pressure of 2.65 bar (Fung et al. 2013). So for the assessment of plume angle among different devices, the value in the stable phase should be more comparable, in which the duration time is longer and the results could be better repeated.

\section{Droplet size distribution}

Droplet size is a factor which correlates with deposition within the nasal cavity based on inertial theory (Newman et al. 2004). Actuation and formulation parameters are the main factors influencing droplet size distribution of nasal sprays, including actuation force (Doughty et al. 2011), stroke length, actuation velocity (Guo et al. 2008), viscosity of the formulation (Dayal et al. 2004) and so on. And it was reported that droplet size distribution varied at the prestable, stable and post-stable stages of spray development (Fung et al. 2013).

According to inertial property theory (Schroeter et al. 2011), the inertia of a droplet is proportional to the square of droplet diameter and the air flow velocity. Larger and rapid droplets have a larger inertial impaction in the anterior nasal cavity. It was proved that larger droplets tend to deposit at the anterior area of the nose cavity from the study by Harris et al. (1988b) and Cheng et al. (2001). However, the tendency would be decreased and even disappear when the plume angle is narrow. On the other hand, smaller droplets with the reduction of droplet inertia tend to follow the air flow streamlines and deposit in the inner area of nasal cavity (Guo et al. 2005). However, if the droplets are too small $(<10 \mu \mathrm{m})$, it will pass through the nasal cavity and enter into the lung which resulted in ineffectiveness of nasal sprays (Inthavong et al. 2014; Suman et al. 2002).

\section{Velocity of emitted droplets}

Emitted droplets enter the nasal cavity by the airstream, which is influenced by the pump emitted strength and the breath flow of the patient together. It was reported that the droplet emitted with higher velocity may cause the anterior and superior deposition of the formulation in the nasal cavity under the effect of the inertial impaction (Engelhardt et al. 2016). However, if the liquid emitted from the devices with swirling spray, the droplet inertia energy can be transferred from its linear component into the radial and tangential components, thereby reducing the inertia of the spray. In addition, the dispersion of the spray could be increased by the swirling spray (Inthavong et al. 2011, 2014). Therefore, higher velocity might be beneficial to the nasal deposition by using the devices with swirling nasal spray. As reported, the Pressurized Olfactory Delivery $(\mathrm{POD} \circledast)$ devices deliver the drug more efficiently to the upper nasal cavity by causing a higher swirling flow rate with pressure operated device. The two studies by the manufacturer demonstrated that POD devices resulted in over 50\% deposition at the olfactory region and enhanced the olfactory delivery efficiency of aerosol in rats as compared with the nasal drops, which was beneficial to the direct nose-to-brain transport of drugs (Hoekman and Ho 2011a, b). However, there were no data available for the suitability of POD technology on macromolecular biological medicine delivery. It might be because biopharmaceuticals showed significant sensitivity to the shear stress during aerosolization and the air-liquid interface strength (Hertel et al. 2015), and these parameters are very important for the stability and bioactivity of biopharmaceuticals. Therefore, the devices with high speed swirling spray might not be suitable for bio-macromolecular drugs.

\section{Formulation factors influencing nasal deposition}

\section{Viscosity}

Viscosity of the nasal spray has an impact on spray characteristics such as droplet size and spray geometry and the nasal deposition. It was reported that nasal formulations with low viscosity tend to deposite distal to the nares compared to viscous formulations (Guo et al. 2005; Sosnowski et al. 2020). Besides, it was found that the higher viscosity is associated with larger droplet size and narrower plume angle, leading to smaller spray area (Kundoor and Dalby 2011; Pu et al. 2014). Moreover, as shown in Fig. 2, for the nasal spray with carboxymethylcellulose (CMC) as viscosity modifier, the spray area decreased linearly and the droplet size $\left(\mathrm{Dv}_{50}\right.$ measured by Malvern's Spraytec $\left.\AA\right)$ increased linearly with viscosity increment of the formulation (Dayal et al. 2004). However, for the carbopol formulation, the relationship between viscosity and spray area couldn't be obtained, which was attributed to different rheological behavior between the formulations containing CMC and carbopol (Dayal et al. 2004). Therefore, it could be speculated that different effects of viscosity on the spray characteristics could be attributed to the diverse viscosity modifiers which presented different rheological behavior. 


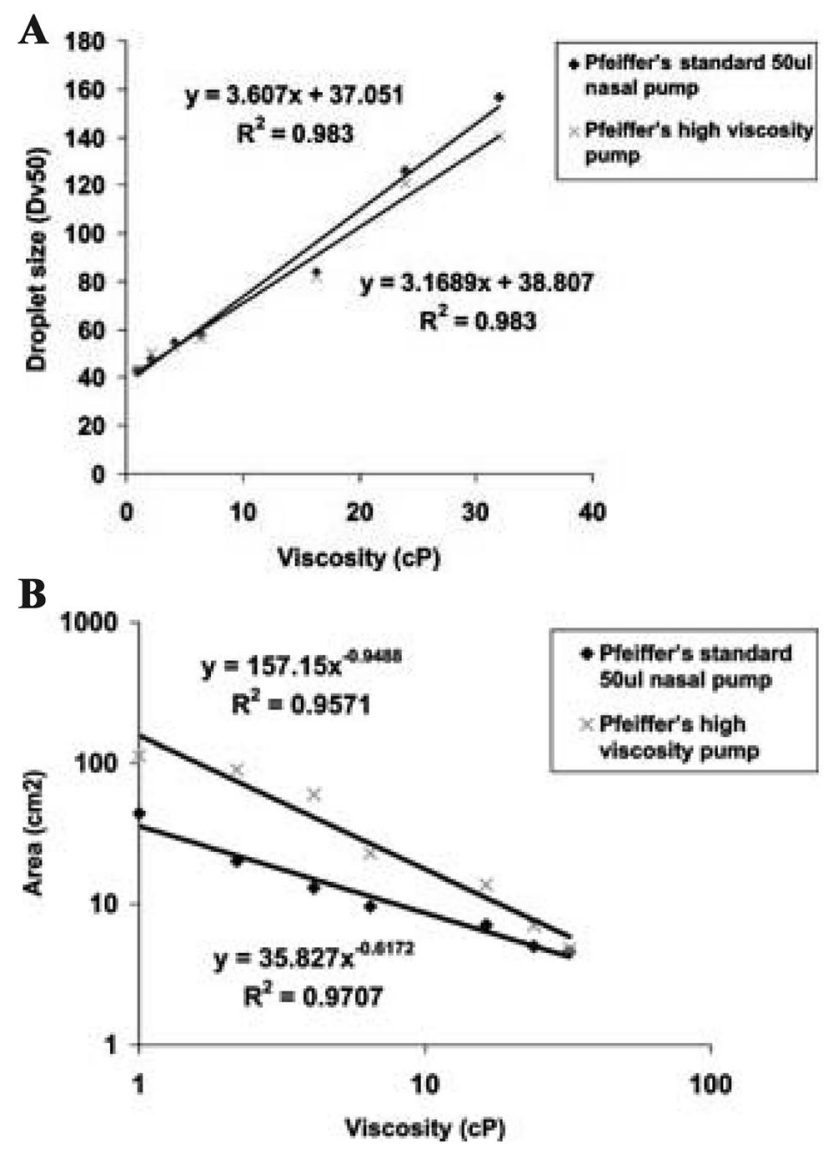

Fig. 2 a Spray droplet size (Dv50) and b spray-pattern surface area versus viscosity using CMC as the viscosity modifier from Pfeiffer's $50 \mu \mathrm{L}$ standard and high-viscosity pumps at an actuation distance of $6 \mathrm{~cm}$. Dv50 and plume area showed a linear relationship with viscosity. Each data point represents the average \pm SEM of three experiments. Adapted from (Dayal et al. 2004 with permission from Elsevier)

\section{Thixotropic property}

Thixotropy is a term describing an isothermal system in which the apparent viscosity decreases under shear stress, followed by a gradual recovery when the stress is removed (Lee et al. 2009). The formulation with thixotropic property changes from viscous state to less viscous state as emitted from the device. And then it will become viscous again when deposited in the nasal cavity. It was reported that the corticosteroid nasal spray inhibited the formulation from flowing out of the nasal cavity attributed to their thixotropic properties, whereas they flowed freely after initial shaking and their viscosity recovered gradually after being dispersed (Sharpe et al. 2003). Similarly, the thixotropic property of mometasone furoate preparation slowed down the formulation transfer from the deposited area to the inferior nasal meatus and throat, extending drug residence time on the surface of the turbinate and middle meatus (Rapiejko et al.
2015). Therefore, it could be concluded that the formulation with thixotropic property would show longer residence time at the deposition site, which is beneficial for prolonged therapeutic effect.

\section{Surface tension}

Surface tension of a formulation frequently influences the nasal deposition by altering other formulation related properties. Dayal et al. (2004) showed that the surface tension of $2 \%$ CMC solution decreased as $0.5-5 \%$ Tween 80 was added, which resulted in the decrease of $\mathrm{Dv}_{50}$ and the alteration of rheology properties such as viscosity and appearance of the thixotropic system. However, it is also indicated that compared with viscosity, surface tension has less impact on the spray characteristics (Guo et al. 2008). It could speculate that if there is an effect of surface tension on the deposition, smaller surface tension would result in larger deposition area of the sprays by decreasing viscosity and particle size of the sprays.

\section{Administration techniques}

\section{Head orientation}

Head orientation has a significant influence on the deposition and efficiency of nasal sprays. It was suggested that the nasal sprays were mainly deposited in the anterior region of the nose when tilting head forward, whereas with tilted head back position, the deposition was significantly deeper and the spray mist could reach the middle area of the nose (Kundoor and Dalby 2011). Besides, tilting head back could prevent the spray from dripping forward and make the spray fully atomized within the nasal passage by administering the nasal spray in line with nasal cavity. Therefore, while using the nasal sprays, tilting the head back is advantageous for drug absorption and could improve the therapeutic effect. However, it was considered that compliance is the most important factor to determine the head orientation (Dhuria et al. 2010). And it was recommended that the upright position is the most comfortable administration method for patients (Guastella et al. 2013).

\section{Administration angle}

The administration angle is an important factor influencing the deposition and efficiency of nasal spray. The administration angle could be divided into sagittal plane angle and coronal plane angle (Warnken et al. 2018). The sagittal plane angle is the insertion angle that the nasal spray device makes away from the horizontal position $\left(0^{\circ}\right.$ in the $\mathrm{x}-\mathrm{y}$ plane), when looking into the side of a person's face 
(Inthavong et al. 2006). And the coronal plane angle is the insertion angle that the nasal spray device makes from the vertical position ( $0^{\circ}$ in the $\mathrm{y}-\mathrm{z}$ plane), when looking into a person's face.

The administration angel at sagittal plane was reported to be an important influencing factor on the deposition of nasal spray in the turbinate region. Foo et al. (2007) showed that the turbinate deposition decreased with the increase of administration angle. The maximum turbinate deposition fraction was $90 \%, 50 \%$ and $30 \%$ at the administration angle of $30^{\circ}, 40^{\circ}$ and $50^{\circ}$ (the plume angle $30^{\circ}$, $55^{\circ}$ and $65^{\circ}$ ), respectively. Similarly, it was reported that with the administration angle increased from 30 to $75^{\circ}$, the percentage of cromolyn sodium nasal spray deposited in the turbinate region decreased from $72.9 \pm 12.4$ to $10.6 \pm 9.3 \%$ (Warnken et al. 2018). In addition, no significant differences in the upper turbinate region deposition were observed with the increase in administration angle (Warnken et al. 2018). Meanwhile, it was indicated that the droplets could better trace through the nasal valve and distribute at the turbinate region at administration angle less than $45^{\circ}$ (Kundoor and Dalby 2011). It could be concluded that the small administration angle at sagittal plane such as $30^{\circ}$ could enhance the distribution of nasal spray in the turbinate region, which is the main absorption region of drug.

The administration angel at coronal plane is another factor influencing the deposition of nasal spray in the turbinate region. From the Warnken et al.'s study, it was found that as the sagittal plane angle was fixed at $30^{\circ}$, turbinate deposition efficiency increased from 73.0 to $97.1 \%$ with the coronal plane angle increased from $0^{\circ}$ to $20^{\circ}$ for a 3D-printed nasal replica cast. And the turbinate deposition efficiency increased from 81.7 to $95.8 \%$ with coronal plane angle increased from $0^{\circ}$ to $15.7^{\circ}$ at the same sagittal plane angle of $30^{\circ}$ for another nasal cast (Warnken et al. 2018). It could be inferred that an appropriate administration angle at coronal plane could enhance the deposition efficiency of nasal spray in the turbinate region.

\section{Spray nozzle insertion depth}

Nasal spray insertion depth has significant effect on the deposition area. It was found that the deposition area was the largest when the nozzle was positioned $10 \mathrm{~mm}$ into the nostril (Kundoor and Dalby 2011). The same conclusion was drawn by Kimbell et al. (2007). However, compared with the influence of head position and administration angle, nozzle insertion depth had a minimum effect on the deposition area, while the average deposition area was in a narrow range of $1.7-2.5 \mathrm{~cm}^{2}$ as the insertion depth increased from 0 to $15 \mathrm{~mm}$ (Kundoor and Dalby 2011).

\section{Breathing profile}

Breathing profile might influence the deposition of nasal spray powered by breath. Guo et al. (2005) observed that the breathing profile had significant effect on the nasal deposition of low viscosity formulation (viscosity $=4.0$ $\mathrm{cP}$ ), while for the high viscosity formulation (viscosity $=18.2 \mathrm{cP}$ ), the effect was not significant in the in vitro study. For low viscosity formulation, the study indicated that an airflow rate of $10 \mathrm{~L} / \mathrm{min}$ increased the upward travel of droplets before gravity causing them to fall to the floor of the nasal cavity. Further increase in airflow rate (i.e., $20 \mathrm{~L} / \mathrm{min}$ ) may have induced turbulence, and drag the droplets in unpredictable direction, thus decrease the nasal deposition. However, the study of Kundoor and Dalby (2010) showed that inhaled flow rate did not have a significant effect on the deposition pattern of nasal spray in a silicone human nose model. Newman et al. (1994) also found that nasal insulin formulation delivered with different application volumes $(80-160 \mu \mathrm{L})$ at gentle or vigorous inhalation air-flows did not result in different effects on blood glucose. Thus, the effect of breathing profile on the deposition of nasal sprays and the followed therapeutic effect might need further detailed studies. As indicated by Guo et al. (2005), if breathing pattern had less impact on the nasal deposition, the patients would have no need to worry about the confusion of usage between two different nasal products, thus decrease the discrepancy of nasal deposition due to the different breathing pattern among patients.

\section{Characterization methods for nasal deposition}

In the guidance of Food and Drug Administration, in vitro methods was recommended to assess the bioavailability and bioequivalence of nasal sprays for local action, as they can discriminate with greater sensitivity and less variability than clinical studies (FDA 2002). Currently, an anatomically correct human nose model combined with an imaging method has been applied to visualize and quantify the deposition of nasal formulations in vitro. Compared with the laborious analysis method that the drug deposition was determined by disassembling the nasal cast and measuring the amount of active drug retained in each area, this method was proven well-controlled. Meanwhile, it was indicated that there was no difference in deposition between a human plastinated head model and volunteers (Le Guellec et al. 2014). The imaging methods available include dye-based, Sar-gelbased, gamma scintigraphy-based and positron emission tomography-based ones. 


\section{Dye-based method}

Many types of dyes could be used to indicate the position and intensity of nasal deposition, such as methylene blue and indigo blue (Mao et al. 2006). Dye-based methods have been applied to compare the regional drug deposition between douching solution and nebulizer by visualizing the staining intensity and area in the nose of operated cadaver models (Valentine et al. 2008). However, solution dripping, solution diffusion and difficulty of dosage quantification are the disadvantages of this method (Xi et al. 2016).

\section{Sar-gel-based imaging analysis method}

Sar-gel, a water-indicating paste, changes its color from white to purple upon contact with water. And it is coated uniformly and completely on the silicone human nose model to indicate the deposition of nasal sprays. Sar-gel is sensitive to water and able to lock in the droplet on it. It was demonstrated that Sar-gel could detect the water mass as low as $0.5 \mu \mathrm{L}$, which might be the smallest water droplet of nasal sprays (Kundoor and Dalby 2010). Formulation dripping or post-deposition spreading (by diffusion) was not observed on a Sar-Gel surface until the single drop volume exceeded 25 $\mu \mathrm{L}$. In addition, it's easy to clean up the model to be reused because the silicone human nose model is hydrophobic and Sar-gel is hydrophilic. In addition, the color change of Sargel is dependent on the water mass, which could be used to quantify the deposition on the region of the nose. Therefore, Sar-gel appears to be an ideal method to visualize and quantify the deposition of the spray droplets.

\section{Gamma scintigraphy-based imaging method}

This technique adopts radioactive tracers such as technetium-99 m or indium-111 to radiolabel preparations (Guo et al. 2005; Laube et al. 2010). The deposition images were acquired using a gamma camera and the color intensity could be processed to reflect the dosage for quantitative comparison. It is an elegant way to gain insights on the actual in vitro or in vivo distribution pattern of dosage forms such as oral (Honkanen et al. 2004), pulmonary (Laube et al. 2010) and nasal (Washington et al. 2000) formulations. Gamma scintigraphy can also be used to evaluate the equivalence of nasal sprays for local action, which is more precise than in vitro testing and expeditious than traditional clinical efficacy studies (Al-Ghananeem et al. 2008). Based on the fact that the labeling radionuclides are not constituents of the drugs, the radionuclides can only be employed to label the carriers of the formulations. Hence, the accuracy of the technique relies on the assumption that the carriers are able to accurately reflect drug deposition. In addition, the method is known to be complicated by the attenuation and scattering of gamma rays in the measurement environment, which also caused deviation of the measurement.

\section{Positron emission tomography (PET)-based imaging method}

The PET is a functional imaging technique used to observe metabolic process of the nuclear medicine in the body (Bailey 2005). The system detects pairs of gamma rays emitted indirectly by a positron-emitting radionuclide tracer, which is introduced into the body via a biologically active molecule. Three-dimensional images of tracer concentration within the body are then constructed by computer analysis. Since the technique is directly used to detect the compound of interest labeled with radionuclides, it can enhance the accuracy of drug deposition when the drug is separated from the carrier and absorbed across the mucosa by specific transport processes or by transcellular diffusion of lipophilic compounds (Bergstrom et al. 1999). Typically, even the deposition of sprays where the dose accounted for 3 or $5 \%$ can be detected by PET technology (Bergström et al. 1995; Lunell et al. 1996). However, one limitation of PET is that PET camera has a finite axial field of view, regularly 10 to $15 \mathrm{~cm}$. This could be compensated by moving the patient stepwise in front of the camera. Another limitation is that the method can't discriminate the radiolabelled metabolites with the original compound.

\section{Conclusion}

Drug deposition is an important factor influencing the absorption and efficiency of nasal sprays in the nasal cavity. Deposition pattern of nasal sprays is dependent on multiple factors including device, formulation and administration technique of patients. Among them, device factors included emitted dose volume of the device, spray pattern and plume geometry, droplet size distribution and velocity of emitted droplets. Viscosity, thixotropic property and surface tension were considered to be the important formulation factors influencing nasal deposition of spray. In addition, administration technique included head orientation, administration angle, spray nozzle insertion depth and breathing profile. And imaging methods could be used to predict and visualize the deposition of nasal formulation. For manufacturers, drug deposition can be improved by device and formulation technologies to get ideal therapeutic effect of nasal sprays. The review provided important theoretical and experimental knowledge to control the deposition pattern of nasal sprays in order to achieve better therapeutic effect in the clinic. 


\section{Compliance with ethical standards}

Conflict of interest The authors declare that they have no conflict of interest.

Statement of human and animal rights This article does not contain any studies with human and animal subjects performed by any of the authors.

Open Access This article is licensed under a Creative Commons Attribution 4.0 International License, which permits use, sharing, adaptation, distribution and reproduction in any medium or format, as long as you give appropriate credit to the original author(s) and the source, provide a link to the Creative Commons licence, and indicate if changes were made. The images or other third party material in this article are included in the article's Creative Commons licence, unless indicated otherwise in a credit line to the material. If material is not included in the article's Creative Commons licence and your intended use is not permitted by statutory regulation or exceeds the permitted use, you will need to obtain permission directly from the copyright holder. To view a copy of this licence, visit http://creativecommons.org/licenses/by/4.0/.

\section{References}

Al-Ghananeem AM, Sandefer EP, Doll WJ, Page RC, Chang Y, Digenis GA (2008) Gamma scintigraphy for testing bioequivalence: a case study on two cromolyn sodium nasal spray preparations. Int $\mathbf{J}$ Pharm 357:70-76. https://doi.org/10.1016/j.ijpharm.2008.01.040

Bailey DL, Townsend DW, Valk PE, Maisey MN (2005) Positron emission tomography: basic sciences. Springer, Secaucus

Bergström M, NordbergElAntoni AMDG, Långström B (1995) Regional deposition of inhaled ${ }^{11} \mathrm{C}$-nicotine vapor in the human airway as visualized by positron emission tomography. Clin Pharmacol Ther 57:309-317. https://doi.org/10.1016/00099236(95)90156-6

Bergstrom M, Cass LM, Valind S, Westerberg G, Lundberg EL, Gray S, Bye A, Langstrom B (1999) Deposition and disposition of ${ }^{11} \mathrm{C}$ zanamivir following administration as an intranasal spray evaluation with positron emission tomography. Clin pharmacokinet 36:33-39. https://doi.org/10.2165/00003088-199936001-00004

Cheng Y, Yeh H, Guilmette R, Simpson S, Cheng K, Swift D (1996) Nasal deposition of ultrafine particles in human volunteers and its relationship to airway geometry. Aerosol Sci Tech 25:274-291. https://doi.org/10.1080/02786829608965396

Cheng YS, Holmes TD, Gao J, Guilmette RA, Li S, Surakitbanharn Y, Rowlings C (2001) Characterization of nasal spray pumps and deposition pattern in a replica of the human nasal airway. J Aerosol Med 14:267-280. https://doi.org/10.1089/089426801524841 99

Dayal P, Shaik MS, Singh M (2004) Evaluation of different parameters that affect droplet-size distribution from nasal sprays using the Malvern Spraytec (R). J Pharm Sci 93:1725-1742. https://doi. org/10.1002/jps.20090

Dhuria SV, Hanson LR, Frey WH II (2010) Intranasal delivery to the central nervous system: mechanisms and experimental considerations. J Pharm Sci 99:1654-1673. https://doi.org/10.1002/ jps. 21924

Doughty DV, Vibbert C, Kewalramani A, Bollinger ME, Dalby RN (2011) Automated actuation of nasal spray products: determination and comparison of adult and pediatric settings. Drug Dev Ind Pharm 37:359-366. https://doi.org/10.3109/03639 045.2010.520321
Durand M, Rusch P, Granjon D, Chantrel G, Prades JM, Dubois F, Esteve D, Pouget JF, Martin C (2001) Preliminary study of the deposition of aerosol in the maxillary sinuses using a plastinated model. J Aerosol Med 14:83-93. https://doi.org/10.1089/08942 680152007936

Engelhardt L, Rohm M, Mavoungou C, Schindowski K, Schafmeister A, Simon U (2016) First steps to develop and validate a CFPD model in order to support the design of nose-to-brain delivered biopharmaceuticals. Pharm Res 33:1337-1350. https://doi. org/10.1007/s11095-016-1875-7

FDA (2002) Nasal spray and inhalation solution, suspension, and spray drug products-chemistry, manufacturing, and controls. U.S. Food \& Drug Administration Web. https://www.fda.gov/media/70857/ download. Accessed 24 Mar 2020

Foo MY, Cheng YS, Su WC, Donovan MD (2007) The influence of spray properties on intranasal deposition. J Aerosol Med 20:495508. https://doi.org/10.1089/jam.2007.0638

Fung MC, Inthavong K, Yang W, Lappas P, Tu J (2013) External characteristics of unsteady spray atomization from a nasal spray device. J Pharm Sci 102:1024-1035. https://doi.org/10.1002/ jps.23449

Gao M, Sun Y, Kou Y, Shen X, Huo Y, Liu C, Sun Z, Zhang X, Mao S (2019) Effect of glyceryl monocaprylate-modified chitosan on the intranasal aabsorption of insulin in rats. J Pharm Sci 108:36233629. https://doi.org/10.1016/j.xphs.2019.07.012

Guastella AJ, Hickie IB, McGuinness MM, Otis M, Woods EA, Disinger HM, Chan HK, Chen TF, Banati RB (2013) Recommendations for the standardisation of oxytocin nasal administration and guidelines for its reporting in human research. Psychoneuroendocrino 38:612-625

Guo Y, Laube B, Dalby R (2005) The effect of formulation variables and breathing patterns on the site of nasal deposition in an anatomically correct model. Pharm Res 22:1871-1878. https://doi. org/10.1007/s11095-005-7391-9

Guo C, Stine KJ, Kauffman JF, Doub WH (2008) Assessment of the influence factors on in vitro testing of nasal sprays using boxbehnken experimental design. Eur J Pharm Sci 35:417-426. https ://doi.org/10.1016/j.ejps.2008.09.001

Harris AS, Ohlin M, Lethagen S, Nilsson IM (1988a) Effects of concentration and volume on nasal bioavailability and biological response to desmopressin. J Pharm Sci 77:337-339. https://doi. org/10.1002/jps.2600770412

Harris AS, Svensson E, Wagner ZG, Lethagen S, Nilsson IM (1988b) Effect of viscosity on particle size, deposition, and clearance of nasal delivery systems containing desmopressin. J Pharm Sci 77:405-408. https://doi.org/10.1002/jps.2600770510

Hertel SP, Winter G, Friess W (2015) Protein stability in pulmonary drug delivery via nebulization. Adv Drug Deliver Rev 93:79-94. https://doi.org/10.1016/j.addr.2014.10.003

Hoekman JD, Ho RJ (2011a) Effects of localized hydrophilic mannitol and hydrophobic nelfinavir administration targeted to olfactory epithelium on brain distribution. AAPS Pharmscitech 12:534 543. https://doi.org/10.1208/s12249-011-9614-1

Hoekman JD, Ho RJ (2011b) Enhanced analgesic responses after preferential delivery of morphine and fentanyl to the olfactory epithelium in rats. Anesth Analg 113:641. https://doi.org/10.1213/ ANE.0b013e3182239b8c

Honkanen O et al (2004) Gamma scintigraphic evaluation of the fate of hydroxypropyl methylcellulose capsules in the human gastrointestinal tract. Eur J Pharm Sci 21:671-678. https://doi.org/10.1016/j. ejps.2004.01.008

Inthavong K, Fung MC, Tong X, Yang W, Tu J (2014) High resolution visualization and analysis of nasal spray drug delivery. Pharm Res 31:1930-1937. https://doi.org/10.1007/s11095-013-1294-y 
Inthavong K, Ge Q, Se CM, Yang W, Tu J (2011) Simulation of sprayed particle deposition in a human nasal cavity including a nasal spray device. J Aerosol Sci 42:100-113

Inthavong K, Tian Z, Li H, Tu J, Yang W, Xue C, Li CG (2006) A numerical study of spray particle deposition in a human nasal cavity. Aerosol Sci Tech 40:1034-1045. https://doi. org/10.1080/02786820600924978

Inthavong K, Yang W, Fung M, Tu J (2012) External and near-nozzle spray characteristics of a continuous spray atomized from a nasal spray device. Aerosol Sci Tech 46:165-177

Khafagy ES, Morishita M, Takayama K (2010) The role of intermolecular interactions with penetratin and its analogue on the enhancement of absorption of nasal therapeutic peptides. Int $\mathbf{J}$ Pharm 388:209-212

Kimbell JS et al (2007) Characterization of deposition from nasal spray devices using a computational fluid dynamics model of the human nasal passages. J Aerosol Med 20:59-74. https://doi.org/10.1089/ jam.2006.0531

Kublik H, Vidgren MT (1998) Nasal delivery systems and their effect on deposition and absorption. Adv Drug Deliver Rev 29:157-177. https://doi.org/10.1016/S0169-409X(97)00067-7

Kundoor V, Dalby RN (2010) Assessment of nasal spray deposition pattern in a silicone human nose model using a color-based method. Pharm Res 27:30-36. https://doi.org/10.1007/s1109 5-009-0002-4

Kundoor V, Dalby RN (2011) Effect of formulation- and administration-related variables on deposition pattern of nasal spray pumps evaluated using a nasal cast. Pharm Res 28:1895-1904. https:// doi.org/10.1007/s11095-011-0417-6

Laube BL, Sharpless G, Shermer C, Nasir O, Sullivan V, Powell K (2010) Deposition of albuterol aerosol generated by pneumatic nebulizer in the sophia anatomical infant nose-throat (SAINT) model. Pharm Res 27:1722-1729. https://doi.org/10.1007/s1109 5-010-0171-1

Le Guellec S et al (2014) Validation of anatomical models to study aerosol deposition in human nasal cavities. Pharm Res 31:228-237. https://doi.org/10.1007/s11095-013-1157-6

Lee CH, Moturi V, Lee Y (2009) Thixotropic property in pharmaceutical formulations. J Control Release 136:88-98. https://doi. org/10.1016/j.jconrel.2009.02.013

Lunell E, Bergström M, Antoni G, Långström B, Nordberg A (1996) Nicotine deposition and body distribution from a nicotine inhaler and a cigarette studied with positron emission tomography. Clin Pharmacol Ther 59:593-594. https://doi.org/10.1016/S0009 -9236(96)90188-5

Mao S, Yang S, Bi D (2006) Pharmacodynamics and potential toxicity of intranasally administrated dipyrone. Biol Pharm Bull 29:13551359. https://doi.org/10.1248/bpb.29.1355

Newman SP, Moren F, Clarke SW (1988) Deposition pattern of nasal sprays in man. Rhinology 26:111-120

Newman SP, Pitcairn GR, Dalby RN (2004) Drug delivery to the nasal cavity: in vitro and in vivo assessment. Crit Rev Ther Drug 21:21-66. https://doi.org/10.1615/CritRevTherDrugCarrierSys t.v21.i1.20

Newman SP, Steed KP, Hardy JG, Wilding IR, Hooper G, Sparrow RA (1994) The distribution of an intranasal insulin formulation in healthy volunteers: effect of different administration techniques. J Pharm Pharmacol 46:657-660
Pu Y, Goodey AP, Fang X, Jacob K (2014) A comparison of the deposition patterns of different nasal spray formulations using a nasal cast. Aerosol Sci Tech 48:930-938. https://doi.org/10.1080/02786 826.2014.931566

Rapiejko P, Sosnowski TR, Sova J, Jurkiewicz D (2015) Deposition of intranasal glucocorticoids-preliminary study. Otolaryngol Pol 69:30-38. https://doi.org/10.5604/00306657.1184545

Schroeter JD, Garcia GJM, Kimbell JS (2011) Effects of surface smoothness on inertial particle deposition in human nasal models. J Aerosol Sci 42:52-63. https://doi.org/10.1016/j.jaero sci.2010.11.002

Sharpe S, Sandweiss V, Tuazon J, Giordano M, Witchey-Lakshmanan L, Hart J, Sequeira J (2003) Comparison of the flow properties of aqueous suspension corticosteroid nasal sprays under differing sampling conditions. Drug Dev Ind Pharm 29:1005-1012. https ://doi.org/10.1081/DDC-120025457

Slater A, Elder D, Fisher C, Charles S, Broughton S (2007) A quality by design approach for the development of a next generation nasal spray delivery system. Allergy 62:488-488

Sosnowski TR, Rapiejko P, Sova J, Dobrowolska K (2020) Impact of physicochemical properties of nasal spray products on drug deposition and transport in the pediatric nasal cavity model. Int $\mathbf{J}$ Pharm 574:118911. https://doi.org/10.1016/j.ijpharm.2019.11891 1

Suman JD, Laube BL, Lin T-c, Brouet G, Dalby R (2002) Validity of in vitro tests on aqueous spray pumps as surrogates for nasal deposition. Pharm Res 19:1-6. https://doi.org/10.1023/A:10136 43912335

Tlaxca JL, Ellis S, Remmele RL Jr (2015) Live attenuated and inactivated viral vaccine formulation and nasal delivery: potential and challenges. Adv Drug Deliver Rev 93:56-78. https://doi. org/10.1016/j.addr.2014.10.002

Ugwoke MI, Verbeke N, Kinget R (2001) The biopharmaceutical aspects of nasal mucoadhesive drug delivery. J Pharm Pharmacol 53:3-21. https://doi.org/10.1211/0022357011775145

Valentine RJ, Athanasiadis T, Thwin M, Singhal D, Weitzel EK, Wormald P-J (2008) A prospective controlled trial of pulsed nasal nebulizer in maximally dissected cadavers. Am J Rhinol 22:390394. https://doi.org/10.2500/ajr.2008.22.3191

Warnken ZN, Smyth HD, Davis DA, Weitman S, Kuhn JG, Williams RO III (2018) Personalized medicine in nasal delivery: the use of patient-specific administration parameters to improve nasal drug targeting using 3D-printed nasal replica casts. Mol pharmaceut 15:1392-1402. https://doi.org/10.1021/acs.molpharmaceut.7b007 02

Washington N, McGlashan JA, Jackson SJ, Bush D, Pitt KG, Rawlins DA, Gill DA (2000) The effect of nasal patency on the clearance of radiolabeled saline in healthy volunteers. Pharm Res 17:733736. https://doi.org/10.1023/a:1007590501540

Xi J, Yuan JE, Yu Z, Nevorski D, Wang Z, Yue Z (2016) Visualization and quantification of nasal and olfactory deposition in a sectional adult nasal airway cast. Pharm Res 33:1527-1541. https://doi. org/10.1007/s11095-016-1896-2

Publisher's Note Springer Nature remains neutral with regard to jurisdictional claims in published maps and institutional affiliations. 